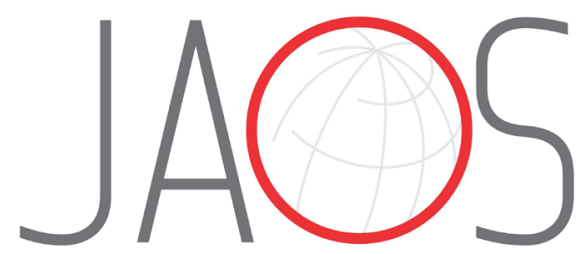
JOURNAL OF APPLIED ORAL SCIENCE

\title{
Action of disinfectant solutions on adaptive capacity and virulence factors of the Candida spp. biofilms formed on acrylic resin
}

Abstract

Mauricio Malheiros BADARÓ ${ }^{1}$

Frank Lucarini BUENO2

Lais Ranieri MAKRAKIS ${ }^{3}$

Camila Borba ARAÚJO ${ }^{3}$

Viviane de Cássia OLIVEIRA ${ }^{3}$

Ana Paula MACEDO ${ }^{3}$ ID

Helena de Freitas Oliveira

PARANHOS $^{3}$ iD

Evandro WATANABE ${ }^{4}$

Cláudia Helena SILVA-LOVATO ${ }^{3}$
Submitted: January 23, 2021 Modification: March 18, 2021 Accepted: April 19, 2021

Corresponding address: Cláudia Helena Lovato da Silva Universidade de São Paulo - Faculdade de Odontologia de Ribeirão Preto - Departamento de Materiais Dentários e Prótese Ribeirão Preto - SP - Brasil. Phone: +55(16)3315-4006 e-mail: chl@forp.usp.br
Understanding the behavior of Candida spp. when exposed to denture disinfectants is essential to optimize their effectiveness. Changes in the virulence factors may cause increased resistance of Candida spp. to disinfectant agents. Objective: To evaluate the microbial load, cellular metabolism, hydrolytic enzyme production, hyphae formation, live cell and biofilm quantification of Candida albicans, Candida tropicalis and Candida glabrata after exposure to disinfectant solutions. Methodology: Simple biofilms were grown on heat-polymerized acrylic resin specimens, and divided into groups according to solutions/strains: distilled water (control); $0.25 \%$ sodium hypochlorite ( $\mathrm{NaOCl} 0.25 \%$ ); $10 \%$ Ricinus communis ( $\mathrm{RC} 10 \%$ ); and $0.5 \%$ Chloramine T (CT $0.5 \%$ ). The virulence factors were evaluated using the CFU count (microbial load), XTT method (cell metabolism), epifluorescence microscopy (biofilm removal and live or dead cells adhered), protease and phospholipase production and hyphae formation. Data were analyzed ( $\alpha=0.05$ ) by one-way ANOVA/ Tukey post hoc test, Kruskal-Wallis test and Wilcoxon test. Results: $\mathrm{NaOCl} 0.25 \%$ was the most effective solution. CT $0.5 \%$ reduced the number of CFUs more than RC $10 \%$ and the control. RC $10 \%$ was effective only against C. glabrata. RC $10 \%$ and CT $0.5 \%$ decreased the cellular metabolism of C. albicans and C. glabrata. Enzyme production was not affected. Hyphal growth in the RC $10 \%$ and CT $0.5 \%$ groups was similar to that of the control. CT $0.5 \%$ was better than RC $10 \%$ against $C$. albicans and $C$. tropicalis when measuring the total amount of biofilm and number of living cells. For C. glabrata, CT $0.5 \%$ was equal to RC $10 \%$ in the maintenance of living cells; RC $10 \%$ was superior for biofilm removal. Conclusions: The CT $0.5 \%$ achieved better results than those of Ricinus communis at $10 \%$, favoring the creation of specific products for dentures. Adjustments in the formulations of RC $10 \%$ are necessary due to efficacy against C. glabrata. The $\mathrm{NaOCl} 0.25 \%$ is the most effective and could be suitable for use as a positive control.

Keywords: Candida. Acrylic resins. Biofilms. Microbial viability. Denture cleansers.

${ }^{1}$ Universidade Federal de Santa Catarina (UFSC), Departamento de Odontologia, Florianópolis, SC, Brasil.

${ }^{2}$ Universidade José do Rosário Vellano (UNIFENAS), Departamento de Odontologia, Alfenas, MG, Brasil.

${ }^{3}$ Universidade de São Paulo (USP), Faculdade de Odontologia de Ribeirão Preto, Departamento de Materiais Dentários e Prótese, Ribeirão Preto, SP, Brasil.

${ }^{4}$ Universidade de São Paulo (USP), Faculdade de Odontologia de Ribeirão Preto, Departamento de Odontologia Restauradora, Ribeirão Preto, SP, Brasil. 


\section{Introduction}

The complete denture is made with acrylic resin and widely used to replace all teeth, restoring function, aesthetics and comfort to the patient. However, acrylic resin in the oral environment favors the adherence of oral debris, bacteria, and fungi. Thus, there is a direct risk relationship between denture use, biofilm and the development of denture stomatitis (DS) ${ }^{1}$ Many individuals are unaware that they have DS, an infection that can aggravate systemic diseases, such as chronic obstructive pulmonary disease, bacterial endocarditis, aspiration pneumonia and gastro-intestinal infection, due the high Candida spp. count. ${ }^{2,3,4}$ Immune response is a determinant of infections caused by Candida spp., which can become even more serious with the exacerbation of the pathogenicity of these microorganisms and imbalance of the individual's immune response. ${ }^{3}$ Candida infections are predominantly caused by C. albicans, but the literature indicates an increasing role for nonalbicans Candida species (C. glabrata, C. tropicalis, C. parapsilosis or $C$. krusei) as infectious agents, which have different adaptive capacity, different susceptibility to antifungal agents ${ }^{3,5}$ and potential for adhesion on acrylic surfaces. ${ }^{6,7}$ Therefore, the relative value of cell surface hydrophobicity and the biofilm biomass of non-albicans Candida species is greater than $C$. albicans, considering that $92 \%$ of the non-albicans Candida species of oral isolates had the capacity to form biofilm against only $78 \%$ of $C$. albicans. ${ }^{8}$ This fact indicates the need for a comprehensive approach to non-albicans species in individuals wearing dentures.

The adaptive capacity of Candida is influenced by virulence factors, such as the adhesion, biofilm formation, microbial load and cell viability, cellular metabolism, hydrolytic enzymes production, and phenotypic changes with formation of hyphae. ${ }^{9,10}$ Change in the adaptive capacity is evident when infection is recurrent after therapy with antimicrobial agents, indicating resistance of the microorganism ${ }^{1}$ and limiting treatment options. Infection control is even more difficult for denture users with inadequate hygiene and the presence of biofilm is clinically significant. Thus, disinfectant solutions have been proposed for the prevention of DS and for microbiota control $^{1,12,13}$ to reduce the need for systemic antifungal use.

Sodium hypochlorite $(\mathrm{NaOCl})$ has proven antimicrobial activity ${ }^{1,13-17}$ and has been recommended as a disinfecting agent for dentures by the American Dental Association (ADA) ${ }^{18}$. Satisfactory results have been reported with $\mathrm{NaOCl}$ at $0.25 \%$ concentration, which maintained the antimicrobial action, the ability to remove the biofilm ${ }^{1,13,16,17}$ and prevent damage to the acrylic resin. ${ }^{19}$ However, $\mathrm{NaOCl}$ may cause allergic reactions, ${ }^{20}$ oxidation of metals, and clothing staining. Alternative disinfectants such as Ricinus communis ${ }^{1,13,16,19,21}$ and Chloramine $T^{1,22-25}$ have been proposed as alternative solutions.

The detergent derived from $R$. communis oil causes loss of cytoplasmic constituents and fungal cell death, damaging the fungal cell wall. ${ }^{26}$ The use of $R$. communis alongside brushing promoted the remission of DS, $1,12,13$ in which the concentration of $10 \%$ of $R$. communis was better than $\mathrm{NaOCl}$ at $0.25 \% .{ }^{13}$ Moreover, a solution of $R$. communis in different concentrations has been used to remove biofilm from complete denture. ${ }^{1,13,21}$ Chloramine T promotes oxidative reactions, enables the hydrolysis of proteins, and destroys the cell material from microorganisms. ${ }^{27}$ It is a common component of oral antiseptics, and, when incorporated into dentifrices is effective at removing denture biofilm; ${ }^{22-24}$ the Chloramine $T$ solution showed efficacy in biofilm removal of the titanium specimens. ${ }^{25}$ However, only one study has evaluated this solution as an immersion agent for the daily hygiene of complete dentures, with promising findings for $0.5 \%$ concentration. ${ }^{1}$

Although there are clinical studies with these solutions, ${ }^{1,13,16}$ this laboratory study is important to prove that the use of these disinfectant solutions does not cause adaptation or resistance of the microorganisms. The originality is the absence of researches verifying the adaptive capacity of Candida spp. regarding virulence and biofilm factors after contact with disinfectants in concentrations with clinical feasibility. Therefore, given the need to establish effective preventive measures against Candida spp., this study aimed to evaluate the influence of $\mathrm{NaOCl}$ at $0.25 \%, R$. communis at $10 \%$ and Chloramine $\mathrm{T}$ at $\mathbf{0 . 5 \%}$ solutions on the microbial load, cellular metabolism, hydrolytic enzyme production, hyphae formation, live cell quantification and biofilm removal of Candida spp. on acrylic resin as alternative disinfectants for dentures against Candida albicans, Candida tropicalis and Candida glabrata. The study hypothesis was that the solutions would not differ 
significantly from each other; however, they would differ from the negative control.

\section{Methodology}

\section{Specimen preparation and experimental design} Heat-polymerized acrylic resin (Artigos Odontológicos Clássico Ltda., São Paulo, SP, Brazil) was mixed, packed in circular molds $(13 \times 3 \mathrm{~mm})$ and conventionally polymerized. ${ }^{17}$ The flask was placed in room temperature water, which reached $65^{\circ} \mathrm{C}$ in 1 hour. Thereafter, the temperature was raised to $100^{\circ} \mathrm{C}$ in half an hour and held for 1 hour, and then lowered to room temperature. The specimens were finished using rotary instruments and 180-grit abrasive paper in a polishing machine (Arotec, Aropol E, Cotia, SP, Brazil).

To simulate the inner surface of the denture, the surface roughness ( $\mathrm{Ra}$ ) was standardized between 2.7 and $3.7 \mu \mathrm{m}^{28}$ with a profilometer (Surftest SJ201P, Mitutoyo Corporation, Kawasaki, Japan). Three readings were made, one in the central portion and two with $2 \mathrm{~mm}$ to the right and left ( 5 "cutoff" of 0.8 $\mu \mathrm{m}$ ) of the center. The specimens were randomly divided into 12 groups $(n=24)$ according to strains frequently isolated in clinical studies. ${ }^{1,16}$ Reference strains were used, which are: C. albicans (ATCC 10231), C. tropicalis (ATCC 750) and C. glabrata (ATCC 2001); and solution [C: distilled water - Negative control; $\mathrm{NaOCl} 0.25 \%: 0.25 \%$ sodium hypochlorite (Injectcenter, Ribeirão Preto, SP, Brazil); RC 10\%: 10\% R. communis (Institute of Chemistry of São Carlos, University of São Paulo, SP, Brazil); CT 0.5\%: 0.5\% Chloramine $\mathrm{T}$ (Lioserum Chemicals, Ribeirão Preto, $\mathrm{SP}$, Brazil)]. ${ }^{1}$ The $R$. communis solution was made by an esterification reaction, consisting of triglycerides containing fatty acids: ricinoleic acid; linoleic acid; stearic acid; palmitic acid; dihydroxystearic acid; licosanoic acid; linolenic acid. ${ }^{22}$ CT $0.5 \%$ solution (tosylchloramide-sodium; molecular weight: 281.69 $\mathrm{g} / \mathrm{L}$; reagent grade; Merck) was prepared according to Arnitz, Nagl, Gottardi29 (2009) by dissolving it in phosphate-buffered saline - PBS ( $\mathrm{pH} 7.1$ ).

In each group, nine specimens were used to assess microbial load (CFU), enzymatic activity and hyphae formation; nine to assess metabolic activity (XTT); and three for fluorescence microscopy. To confirm the sterility of the procedures and materials, three sterilized specimens were put in sterilized culture medium, and, to confirm biofilm formation, another three specimens contaminated by Candida spp. and not immersed in disinfection solution were used. Before biofilm formation, the specimens were sterilized by irradiation in a microwave oven (650W; 6 minutes). ${ }^{30}$ The experiments were performed in triplicate on three different occasions.

\section{Mono-species biofilm formation}

Candida strains were reactivated in Sabouraud Dextrose Agar (HiMedia Laboratories Pvt. Ltda., Mumbai, India) at $37^{\circ} \mathrm{C}$ (48 hours), transferred to Sabouraud Dextrose Broth (HiMedia Laboratories Pvt. Ltda, Mumbai, India) and incubated $\left(37^{\circ} \mathrm{C} / 18\right.$ hours). An aliquot of the culture medium with the reactivated strains was diluted in PBS (100× dilution; $990 \mu \mathrm{L}$ PBS plus $10 \mu \mathrm{L}$ of the microorganism suspension), from which $10 \mu \mathrm{L}$ were transferred to the Neubauer chamber (HBG). The standardization in $1 \times 10^{6} \mathrm{CFU} / \mathrm{mL}$ of strains was done after counting the outer quadrants in the Neubauer chamber under a microscope, in which the average of the counts is multiplied by the dilution and converted to $\mathrm{mL}$. In a laminar flow chamber, the specimens were placed in 24-well culture plates with $1.5 \mathrm{~mL}$ of the inoculated culture medium and incubated (370 C; 90 minutes; $75 \mathrm{rpm}$ ). The specimens and wells were washed with phosphate buffered saline (PBS) to remove the non-adherent microorganisms, filled with sterile culture medium $(1.5 \mathrm{~mL})$ and incubated for the formation and growth of biofilm at $37^{\circ} \mathrm{C}$ for 48 hours under $75 \mathrm{rpm}$ agitation. After the first 24 hours of incubation, half of the culture medium was replaced with the same amount of sterile medium (to avoid saturation), which remained for another 24 hours to complete the biofilm formation cycle.

\section{Evaluation of microbial load}

After the mono-species biofilms growth, the specimens were immersed in the disinfectant solutions (20 minutes), 1,12,13,16,17 rinsed in PBS (three times) and transferred to test tubes containing Letheen medium (Difco Laboratories Inc., Detroit, Michigan, USA). The tubes were placed in an ultrasonic vessel (20 minutes; 200 Watts - Altsonic, Clean 9CA, Ribeirão Preto, SP, Brazil) and Vortex agitator (1 minute - Phoenix ${ }^{\circledR}$ AP56, Ind. and Com., Araraquara, SP, Brazil). Serial dilutions $\left(10^{\circ}\right.$ to $\left.10^{-3}\right)$ were seeded in Sabouraud Dextrose Agar and incubated $\left(37^{\circ} \mathrm{C} ; 48\right.$ hours). The following formula was used to calculate the microbial load: $\mathrm{CFU} / \mathrm{mL}=$ number of colonies $\times 10^{\mathrm{n}} / \mathrm{q}$, where $\mathrm{n}$ 
is the absolute value of dilution $(0,1,2$, or 3$)$ and $\mathrm{q}$ is the quantity $(\mathrm{mL})$ pipetted for each dilution at inoculation $(0.05 \mathrm{~mL})$. After 24 hours of incubation, the aliquots were used in hydrolytic enzyme and hyphae formation assays.

\section{Evaluation of cell metabolism}

The cell metabolism was evaluated by XTT assay [2,3-bis (2-methoxy-4-nitro-5-sulfophenyl)$2 \mathrm{H}$-tetrazolium-5-carboxanilide]. The specimens with biofilm growth were subjected to disinfection procedures and transferred to sterile 24-well culture plates containing a solution composed of PBS supplemented with $100 \mathrm{mM}$ glucose ( $948 \mu \mathrm{L}$; Sigma Aldrich, Sigma-Aldrich Corporation, St Louis, Missouri, USA), XTT solution and menadione (252 $\mu \mathrm{L}$; Sigma Aldrich, Sigma-Aldrich Corporation, St Louis, Missouri, USA). ${ }^{31}$ The plates were protected from light during incubation $\left(37^{\circ} \mathrm{C}, 2 \mathrm{~h}\right)$. Subsequently, a $100-\mu \mathrm{L}$ aliquot was transferred from each well to 96-well plates, in triplicate, for three readings in a microplate reader (Multiskan GO, Thermo Fisher Scientific, Waltham, Massachusetts, USA) at $492 \mu \mathrm{m} .^{31}$

\section{Evaluation of enzyme production and hyphae formation}

After the biofilm had formed for 48 hours, the specimens were exposed to disinfectant solutions and transferred to the Letheen culture medium, and the tube was incubated for 24 hours. Next, the cellular concentration was counted in a Neubauer chamber. The cell suspension ( $1 \mathrm{~mL}$ ) was centrifuged (6000 rpm, 5 minutes). The supernatant was destined for proteinase analysis and the pellet, for phospholipase analysis. For proteinase quantification the EnzChek ${ }^{\circledR}$ Protease Assay fluorimetric kit (Molecular Probe E6638, Eugene, Oregon, USA) was used according to the manufacturer's instructions. Fluorescence was assessed with a microplate reader (Synergy II, BioTek Instruments, Winooski, VT, USA; excitation: $485 \mu \mathrm{m}$; emission: $538 \mu \mathrm{m}$ ). The values obtained were used in linear equations derived from standard curves, with the enzymatic activity in $\mu \mathrm{L} / \mathrm{mL}$. For phospholipase analysis, the fluorimetric kit Amplex ${ }^{\circledR}$ Red Phosphatidylcholine-Specific Phospholipase C Assay (Molecular Probe, Eugene, Oregon, USA) was used according to the manufacturer's instructions to transfer the working solution and cell lysate to a 96-well plate, in triplicate, which was protected from light, incubated $\left(37^{\circ} \mathrm{C} ; 3\right.$ hours), and then read in a microplate reader (excitation: $544 \mu \mathrm{m}$; emission: 590 $\mu \mathrm{m})$. The values provided were compared with the fluorescence values of the positive controls provided by the manufacturer.

To assess hyphae formation, $3 \times 10^{6}$ cells/ $\mathrm{mL}$ were transferred into $5 \mathrm{~mL}$ of hyphal-growth-inducing medium (medium 199; LGC Biotechnology, Cotia, SP, Brazil) containing $10 \%$ of the fetal bovine serum (LGC Biotechnology, Cotia, SP, Brazil) and incubated at $37^{\circ} \mathrm{C}$ under agitation of $80 \mathrm{rpm}$ for 3 hours. A cell count (yeast + hyphae) was performed in a Neubauer chamber under an optical microscope (10x to $40 \times$ objective - Bio-Focus Saintifik, Petaling Jaya, Malásia). The formula used was hyphae/ $\mathrm{mL}=\mathrm{S} / 4 \times \mathrm{D} \times 10^{4}$, where $\mathrm{S}$ is the sum of the major quadrants (Neubauer chamber); $\mathrm{D}$ is the dilution used for counting $(10 \times)$; $10^{4}$ is the correction factor for unit $(\mathrm{mL})$.

\section{Quantification of total biofilm and living cells}

Epifluorescence microcopy was used to assess the presence of viable and dead cells adhered on the surface of the specimens. After disinfection, specimens ( $n=3$, per group/ strain) were transferred to a 24well plate containing $1.2 \mathrm{~mL}$ of Live/Dead ${ }^{\circledR}$ dye (Live/ Dead $^{\circledR}$ BacLight $^{\text {TM }}$ kit - Life Technologies of Brazil Com. Ind. Prod. Biotec. Ltda., Itapevi, SP, Brazil). ${ }^{31}$ The plate was incubated at room temperature for 15 minutes under light protection. The specimens were placed on individual coverslips for analysis under an inverted fluorescence microscope with appropriate filters: FS38HE (green staining); FS43HE (red staining) and a $63 \times$ objective (inverted microscope Observer A1 - Carl Zeiss, Oberkochen, Germany). The specimen manipulation, sterile and individual forceps were used only contacting the sides and avoiding the analysis surface. The different cell stains were used to quantify the live (stained in green; Syto 9) and dead (stained red; Iodide) microorganisms, and the sum of the two to quantify the total biofilm present on the surface of the specimen. Twenty random images of the surface of each specimen were captured under a microscope (63× magnification; software Zen Lite 2.3 - Carl Zeiss, Oberkochen, Germany). The AxioVision software program (AxioVision release 4.8.2 - Carl Zeiss, Oberkochen, Germany) was used to measure the total image area $\left(13733.82 \mathrm{~mm}^{2}\right)$ and the stained areas. The calculation of live cells' area considered the difference between the green and the red (dead cells) pigmented area. ${ }^{31}$ Then, the following formula 
was applied for conversion to percentage: Percentage of live cells $=$ Live cells' area/Total image area $\times 100$; for the calculation of the total biofilm area, only the value of the area of the cells stained green was used. Total biofilm percentage $=$ Biofilm area/Total image area $\times 100 . .^{31}$

\section{Data analysis}

After verifying a normal (Shapiro-Wilk test) and homogeneous (Levene test) distribution, the data were analyzed ( $\alpha=0.05$ ) as follows: ANOVA (one-way) and the Tukey post hoc test for microbial load; the Kruskal-Wallis test and stepwise step-down post hoc test for cell metabolism; the Kruskal-Wallis test for enzyme production and hyphae formation; and the Kruskal-Wallis and Wilcoxon test for comparison of the solutions and the living biofilm, and the total biofilm, respectively; descriptive analyses were used for the fluorescence images. SPSS 21.0 (SPSS Inc.) was used considering a $95 \%$ confidence interval.

\section{Results}

\section{Microbial load and cell metabolism}

The $\mathrm{NaOCl} 0.25 \%$ reduced to zero the CFU count and the cellular metabolism of all Candida species. СТ0.5\% was more effective in decreasing the CFU count when compared with RC $10 \%$ and the negative control. RC $10 \%$ differed from the distilled water (negative control) only against $C$. glabrata (Figure 1). RC $10 \%$ and CT $0.5 \%$ decreased the cellular metabolism of C. albicans and C. glabrata in a similar manner, but, for $C$. tropicalis, CT $0.5 \%$ was more effective (Figure 2).

\section{Enzyme production and hyphae formation}

Only C. glabrata showed increased proteinase production after immersion in all solutions tested when compared with negative control (Figure 3). No difference was found in phospholipase production by Candida spp. after immersion of the specimens in the different disinfectant solutions (Figure 4). The $\mathrm{NaOCl} 0.25 \%$ reduced hyphal growth to zero. Hyphal growth in the other groups of solutions was similar to that in the control (Figure 5). Even though they were statistically similar, the values of СТ0.5\% were lower than those of the RC10\%.

\section{Quantification of total biofilm and living cells adhered}

$\mathrm{NaOCl} 0.25 \%$ showed the best results. CT $0.5 \%$ was better than RC $10 \%$ against C. albicans and C. tropicalis for the total amount of biofilm and number of living cells. For C. glabrata, CT $0.5 \%$ was equal to RC $10 \%$ in the maintenance of living cells, where as RC $10 \%$ was better for biofilm removal (Table 1 ).

Qualitative analyses of the epifluorescence microscopy images indicated that $\mathrm{NaOCl} 0.25 \%$ removed almost $100 \%$ of the cells from the different Candida species, and the cells that remained adhered were dead. For the control group, a large quantity of living cell biofilm was seen covering the specimen. The images of the specimens after immersion in Ricinus communis and Chloramine $\mathrm{T}$ demonstrated the presence of biofilm with live cells (green color) and dead cells (red color), indicating the intermediate action of these solutions (Figure 6).

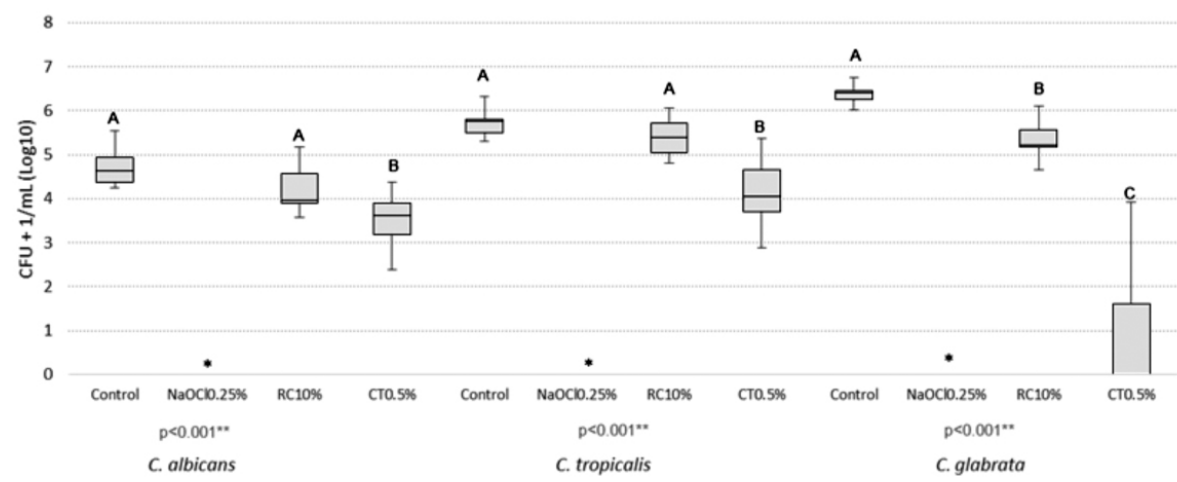

${ }^{*}$ Sodium hypochlorite (NaOCl $0.25 \%$ ) reduced the number of $\mathrm{CFU}$ to zero; ${ }^{* \star}$ Anova (one-way); post-test of Tukey; ${ }^{\mathrm{AB}}$ Equal capital letters indicate statistical similarity between groups.

Figure 1- Comparative analysis of microbial load (CFU $+1 / \mathrm{mL}$, log10) of Candida spp. after immersion of the specimens in the disinfectant and control solutions 


\section{Discussion}

In this study, ATCC strains were used to reduce the great diversification of factors influencing the analyzed variables, such as the expressive variability among organisms (hosts/ human physiology). As well as between clinical strains of the same species of Candida, which can show differences in the cell surface hydrophobicity and adhesion, 7,32 contributing in several states of disease in the human host, since superficial until and systemic infections. ${ }^{6}$ Thus, this study cannot provide a representation of the microorganisms found in the oral cavity, due to its non-clinical origin. However, it can be considered the first step towards an in-depth understanding of the mechanisms that permeate the relationship between Candida spp. and

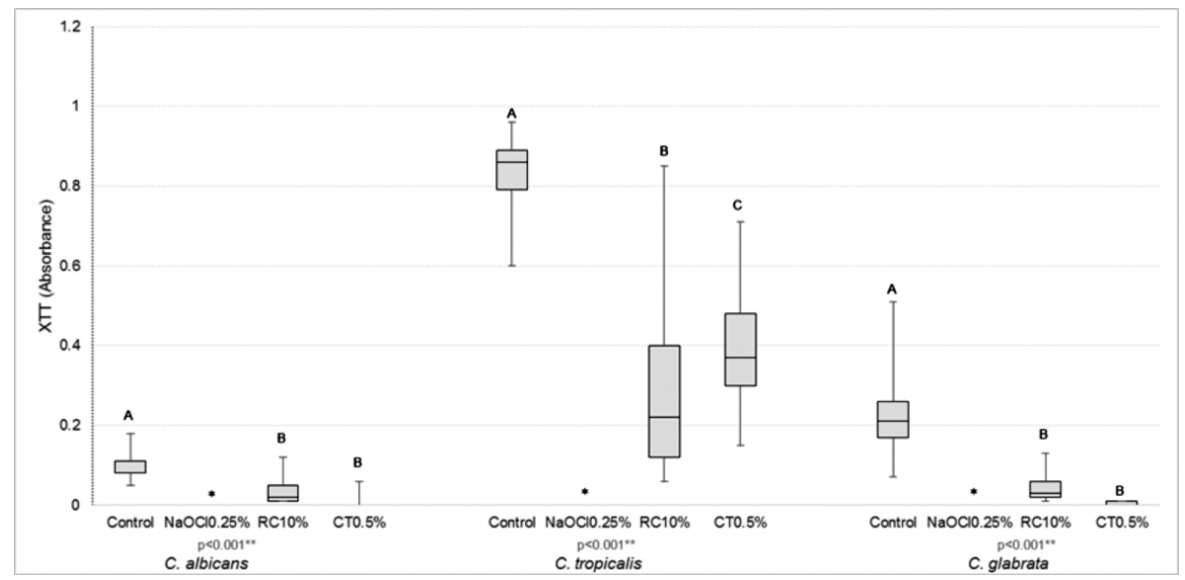

* Sodium hypochlorite $(\mathrm{NaOCl} 0.25 \%)$ reduced the number of metabolic activity to zero; ${ }^{*}$ Kruskal-Wallis, stepwise step-down post-test; ${ }^{A B}$ Equal capital letters indicate statistical similarity between groups.

Figure 2- Comparative analysis of metabolic activity (absorbance $492 \mathrm{~nm}$ ) of Candida spp. after immersion of the specimens in the disinfectant and control solutions

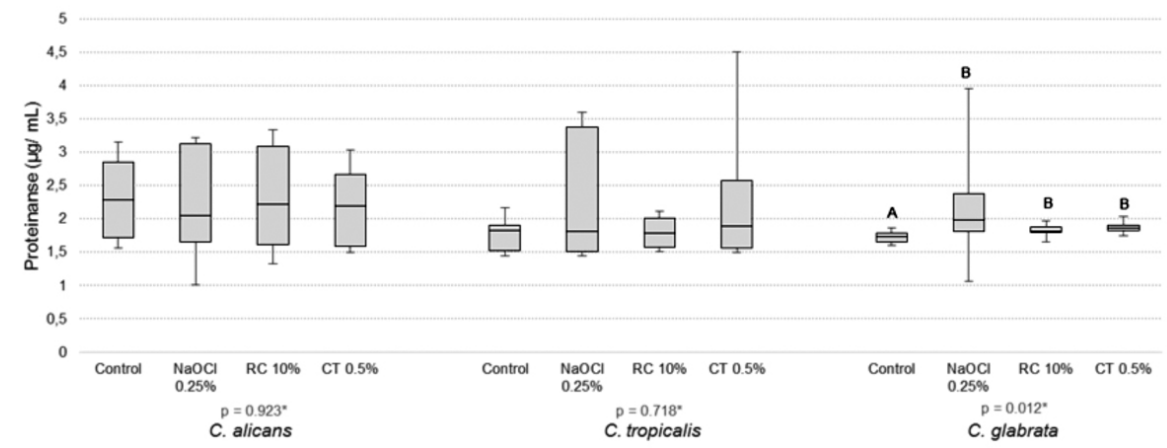

${ }^{*}$ Kruskal-Wallis test and post-test stepwise step-down; ${ }^{A B}$ Equal capital letters indicate statistical similarity between groups.

Figure 3- Comparison of proteinase $(\mu \mathrm{g} / \mathrm{mL}$ ) production by Candida spp. after immersion of the specimens in the disinfectant solutions and water (Control)

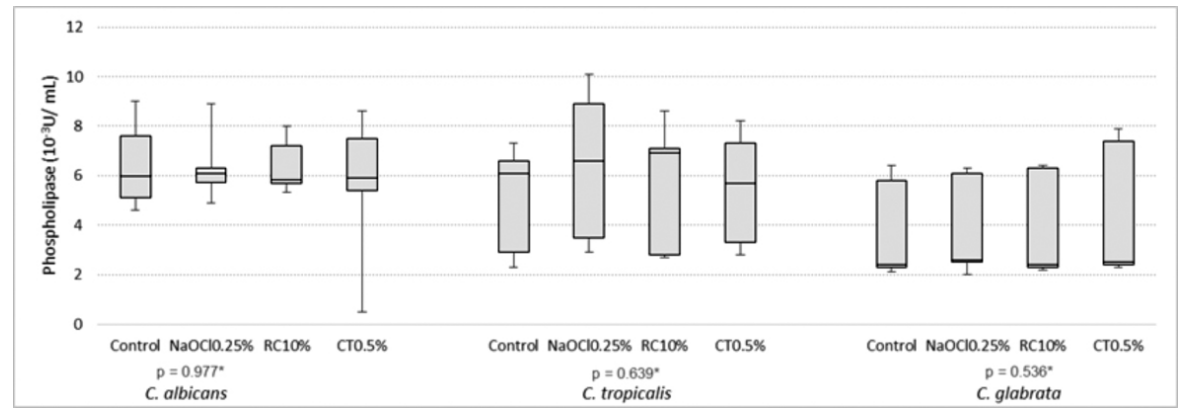

*Kruskal-Wallis test.

Figure 4- Comparison of phospholipase $\left(10^{-3} \mathrm{U} / \mathrm{mL}\right)$ production by Candida spp. after immersion of the specimens in the disinfectant solutions and water (Control) 
Table 1- Comparison (mean and SD, Median and $\mathrm{Cl}$ ) of the living biofilm area and total biofilm area, in percentage, after immersion of the specimens in the disinfectant and control solutions

\begin{tabular}{|c|c|c|c|c|c|c|c|c|c|}
\hline \multirow[t]{2}{*}{ Groups } & \multicolumn{3}{|c|}{ C. albicans } & \multicolumn{3}{|c|}{ C. tropicalis } & \multicolumn{3}{|c|}{ C. glabrata } \\
\hline & $\begin{array}{l}\text { Living } \\
\text { biofilm }\end{array}$ & Total biofilm & $\mathbf{p}^{\star *}$ & Living biofilm & Total biofilm & $\mathbf{p}^{* *}$ & $\begin{array}{l}\text { Living } \\
\text { biofilm }\end{array}$ & Total biofilm & $\mathbf{p}^{* *}$ \\
\hline \multirow[t]{2}{*}{$\mathrm{C}$} & $50.31 \pm 19.85$ & $51.31 \pm 19.34$ & 0.001 & $13.65 \pm 4.06$ & $14.98 \pm 3.7$ & 0.000 & $16.07 \pm 9.22$ & $38.36 \pm 8.12$ & 0.00 \\
\hline & $\begin{array}{c}57.5 \\
(41.0 ; 59.6)^{\mathrm{Aa}}\end{array}$ & $\begin{array}{c}57.72 \\
(42.3 ; 60.4)^{\mathrm{Ab}}\end{array}$ & & $\begin{array}{c}14.0 \\
(11.7 ; 15.5)^{\mathrm{Aa}}\end{array}$ & $\begin{array}{c}15.4 \\
(13.2 ; 16.7)^{\mathrm{Ab}}\end{array}$ & & $\begin{array}{c}18.3 \\
(11.8 ; 20.4)^{\mathrm{Aa}}\end{array}$ & $\begin{array}{c}36.1 \\
(34.6 ; 42.2)^{\mathrm{Ab}}\end{array}$ & \\
\hline \multirow{2}{*}{$\begin{array}{l}\mathrm{NaOCl} \\
0.25 \%\end{array}$} & $0(-;-) \dagger^{a}$ & $3.83 \pm 3.25$ & 0.000 & $0(-;-) \dagger^{a}$ & $1.28 \pm 1.21$ & 0.000 & $0(-;-) \dagger^{a}$ & $0.14 \pm 0.21$ & 0.008 \\
\hline & & $\begin{array}{c}3.23 \\
(2.3 ; 5.4)^{\mathrm{Db}}\end{array}$ & & & $\begin{array}{c}1.0 \\
(0.7 ; 1.8)^{\mathrm{cb}}\end{array}$ & & & $\begin{array}{c}0.0 \\
(0.04 ; 0.2)^{\mathrm{Db}}\end{array}$ & \\
\hline \multirow[t]{2}{*}{ RC $10 \%$} & $10.31 \pm 6.64$ & $11.58 \pm 7.66$ & 0.000 & $6.67 \pm 2.02$ & $8.26 \pm 1.85$ & 0.000 & $0.96 \pm 1.21$ & $3.97 \pm 1.09$ & 0.000 \\
\hline & $\begin{array}{c}9.7 \\
(7.2 ; 13.4)^{\mathrm{Ba}}\end{array}$ & $\begin{array}{c}10.4 \\
(8.0 ; 15.2)^{\mathrm{Bb}}\end{array}$ & & $\begin{array}{c}6.8 \\
(5.7 ; 7.6)^{\mathrm{Ba}}\end{array}$ & $\begin{array}{c}7.9 \\
(7.4 ; 9.1)^{\mathrm{Bb}}\end{array}$ & & $\begin{array}{c}0.32 \\
(0.4 ; 1.5)^{\mathrm{Ba}}\end{array}$ & $\begin{array}{c}4.07 \\
(3.5 ; 4.5)^{\mathrm{cb}}\end{array}$ & \\
\hline \multirow[t]{2}{*}{ CT $0.5 \%$} & $0.44 \pm 0.67$ & $7.34 \pm 6.23$ & 0.000 & $0.03 \pm 0.1$ & $1.56 \pm 0.9$ & 0.000 & $2.6 \pm 3.19$ & $20.91 \pm 10.15$ & 0.000 \\
\hline & $\begin{array}{c}0.0 \\
(0.12 ; 0.7)^{\mathrm{ca}}\end{array}$ & $\begin{array}{c}5.7 \\
(4.4 ; 10.2)^{\mathrm{cb}}\end{array}$ & & $\begin{array}{c}0.0 \\
(-0.01 ; 0.08)^{\mathrm{Ca}}\end{array}$ & $\begin{array}{c}1.6 \\
(1.1 ; 2.0)^{\mathrm{cb}}\end{array}$ & & $\begin{array}{c}0.2 \\
(1.1 ; 4.1)^{\mathrm{Ba}}\end{array}$ & $\begin{array}{c}19.45 \\
(16.2 ; 25.7)^{\mathrm{Bb}}\end{array}$ & \\
\hline$p^{*}$ & $<0.001$ & $<0.001$ & & $<0.001$ & $<0.001$ & & $<0.001$ & $<0.001$ & \\
\hline
\end{tabular}

† the sanitizer reduced the biofilm to zero. * Kruskal-Wallis test. AB Equal capital letters indicate statistical similarity between lines; ** Wilcoxon test. ab Equal lowercase letters indicate statistical similarity between columns.

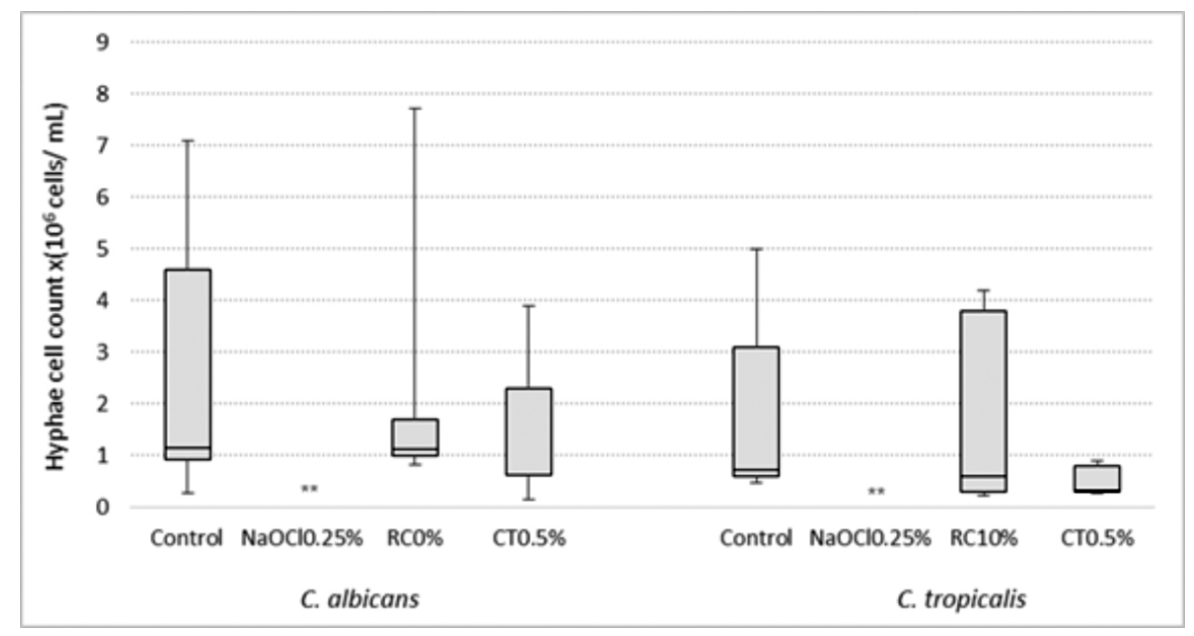

${ }^{*}$ Kruskal-Wallis test; ${ }^{* *} 0.25 \%$ sodium hypochlorite reduced the number of cells in the form of hyphae to zero.

Figure 5- Comparison hyphae cell count $\left(\times 10^{6} \mathrm{cells} / \mathrm{mL}\right)$ of Candida spp. after immersion of the specimens in the disinfectant solutions and water (Control)

disinfectant agents for dentures. Future researches using mixed biofilms and strains with clinical origin can be proposed to provide the representativeness and clinical viability of the process of controlling Candida species in users of dentures.

The hypothesis was partially accepted. The $\mathrm{NaOCl}$ $0.25 \%$ presented the highest efficiency, and the experimental groups (RC $10 \%$ and CT $0.5 \%$ ), in some situations, were similar to the negative control (distilled water). $\mathrm{NaOCl}$ was the most effective in this study, and the results were consistent with the literature because of its demonstrated in vivo and in vitro antimicrobial efficacy, ${ }^{1,13,16,17}$ adequate removal of biofilm, satisfaction of use by denture users, ${ }^{13}$ remission of denture stomatitis, ${ }^{1,13}$ and acceptable changes in the mechanical properties of the heat-polymerized acrylic resin. ${ }^{19}$ Therefore, the $\mathrm{NaOCl}$ at $0.25 \%$ could be considered the positive control or gold standard in other research.

$R$. communis was efficient only against C. glabrata, having a lesser effect than the other solutions. The literature shows different results with $R$. communis, with a study that corroborates the results found in this study ${ }^{12}$ and other that indicates promising results. ${ }^{13,16,17}$ $R$. communis had a minimum inhibitory concentration of $0.0781 \%$ for C. albicans and C. glabrata and, when incorporated into a dentifrice, had a significant effect against bacteria (S. mutans; $B$. subtilis) that are important in biofilm formation. ${ }^{22}$ The contrasting results 


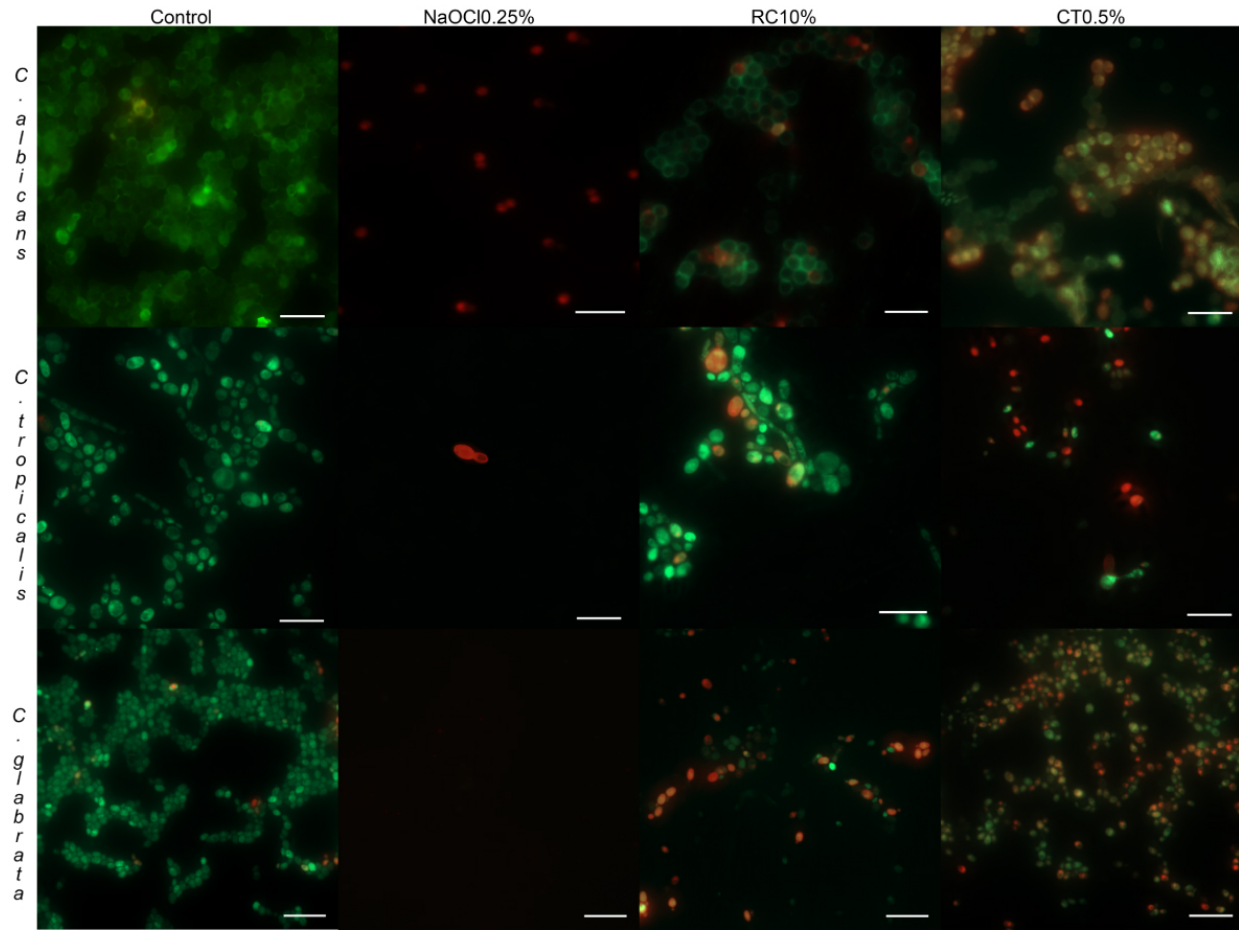

Figure 6- Epifluorescence microscopy images of the $C$. albicans, $C$. tropicalis and C. glabrata biofilm in the specimens after immersion in disinfectant and negative control (Scale bar $=20 \mu \mathrm{m})$

may come from differences in the susceptibility of the microorganisms when in contact with the disinfectants or from methodological differences. The effects of $R$. communis after long periods of immersion (overnight, 8 hours) could differ, and mixed biofilms could also lead to different results. Therefore, additional studies are necessary once $R$. communis is a natural products and it can be one therapeutic alternatives in the treatment of denture stomatitis ${ }^{1,13}$ with low-cost and lower adverse effects as compared to antifungal drugs. CT 0.5\% was better than RC $10 \%$, and the negative control in terms of decreasing microbial load. Verardi, et al. ${ }^{25}$ (2016) also reported a reduction of $\mathrm{CFU} / \mathrm{mL}$ with titanium specimens after using the Chloramine $\mathrm{T}$ solution, which destroys the cellular material or disrupts important cellular processes of the microorganisms by oxidative reactions. ${ }^{27}$ Microorganisms do not become resistant to Chloramine $T$ as can happen with antibiotics and is effective even at low concentrations. ${ }^{27}$

The data on cellular metabolism confirmed the findings on microbial load. The $\mathrm{NaOCl} 0.25 \%$ had $100 \%$ effectiveness for both variables, and these results were in accordance with the literature. The solution of $\mathrm{NaOCl}$ at $1 \%$ (immersion time for 10 seconds) reduced the microbial load of Candida and decreased the cellular metabolism by $98 \%$ in a mixed biofilm model (C. albicans, C. glabrata and S. mutans $)^{28}$, and caused $88 \%$ of the reduction in the $C$. albicans metabolism (simple biofilm) after 90 seconds of immersion. ${ }^{15}$ These findings confirm the feasibility of using $\mathrm{NaOCl}$ at $0.25 \%$ as a positive control with a 20-minute immersion time, since the efficacy was similar to that of higher concentrations. $R$. communis reduced the metabolism of Candida spp., but it was only significant enough to decrease the microbial load of C. glabrata. RC $10 \%$ and CT $0.5 \%$ had similar effects on the cellular metabolism of this specie but differed in terms of microbial load. Thus, only CT $0.5 \%$ presented coherent results regarding the reduction in cellular metabolism and microbial load. Studies using the same concentration of these solutions are scarce, limiting the available information about their mechanisms of action against Candida albicans and non-albicans.

The solutions did not change the hydrolytic enzyme production (proteinase and phospholipase) from $C$. albicans or $C$. tropicalis. One of the enzymatic functions is to allow the fungus to invade and cause damage to tissues. ${ }^{10}$ The maintenance of the production rates of these enzymes was similar to that of the negative control (distilled water) when C. albicans and C. tropicalis were exposed to hygiene solutions. This result can be considered good, since the solutions did not increase the pathogenicity of these species in the concentrations and immersion period: used in this study. However, $C$. glabrata showed an increase in proteinase production when exposed to all solutions. This result suggests a greater specific capacity of this species to react to a given 
stimulus. ${ }^{33}$ This characteristic can influence the survival or persistence of the microorganism between an initial exposure to an antimycotic agent and the acquisition of mutations that confer resistance, an adaptive response. C. glabrata has a complex population structure, with genomic variants that may arise during the process of adaptation to environmental changes and persist over time, giving this species a greater pathogenicity. ${ }^{11}$ Different results were reported by Marcos-Arias, et al. ${ }^{34}$ (2011), who stated that oral samples of Candida spp. showed low levels of proteinase production $(<30 \%)$. According to Gümrü, et al. ${ }^{35}$ (2006) only C. albicans showed changes in phospholipase production when compared with non-albicans species. Samaranayake, Raeside and Macfarlane ${ }^{36}$ (1984) indicated that $C$. tropicalis and C. glabrata did not produce detectable phospholipases, only $C$. albicans were phospholipasepositive.

The hyphae contribute to increasing the mass of Candida biofilm, and consequently increase the difficulty of removal ${ }^{37}$ and the capacity of invasion of the tissues. ${ }^{10}$ The hyphae formation and the production of proteinases are regulated in a coordinated way, since the cells of C. albicans in the form of hyphae require the support of hydrolytic enzymes to be totally invasive in vivo. ${ }^{10}$ Although the formation of hyphae does not occur with all Candida species, the synergism between the species guarantees adhesion and infection. ${ }^{38}$ Staniszewska, et al. ${ }^{38}$ (2012) reported that, in the blastoconidia form, the number of enzymes produced was reduced compared with situations in which the germ tube, pseudo-hyphae and true hyphae were observed. Thus, the non-significant alteration in proteinase production by $C$. albicans can be attributed to the lack of increase in hyphae after the contact with the disinfectant solutions in the present study. This was not the case for C. glabrata, which does not form hyphae, implying that this species has other means of producing proteinase, explaining the increase observed. The tests performed for these variables were carried out concomitantly with the same cellular content of each sample, reinforcing this hypothesis.

For biofilm removal and promotion of cell death, $\mathrm{NaOCl}$ $0.25 \%$ was the most effective solution. This finding is important since dead cells on the surface of the dentures act as an aggregation agent for the adhesion of new microorganisms and since the effective removal of biofilm is essential for the control of the inflammation promoted by Candida. This result is consistent with those of Silva, et al. ${ }^{39}$ (2011) and Gama, et al. ${ }^{14}$ (2015), who evaluated the presence of live cells and the ability to remove $C$. albicans biofilm after immersion in higher concentrations of $\mathrm{NaOCl}$. The authors recommended an immersion time of 5 and 10 minutes, respectively, while the current study used an immersion time of 20 minutes, demonstrating that $\mathrm{NaOCl}$ can be effective at lower concentrations by remaining in contact with the biofilm for longer. The use of lower concentrations reduces the potential for damage to the dentures, especially the surface roughness, which would lead to higher adhesion of microorganisms. Badaró, et al. $^{19}$ (2017) reported that the roughness of heatpolymerized acrylic resin remained clinically acceptable during immersion in $\mathrm{NaOCl} 0.25 \%$.

Regarding biofilm removal, RC $10 \%$ reduced the amount of all species when compared with the negative control, but CT $0.5 \%$ was more effective against $C$. albicans and $C$. tropicalis, and less effective against $C$. glabrata. This may be because of the lack of hyphae in this species, which is thus more easily eliminated by the detergent action of $R$. communis. Sánchez-Vargas, et al. $^{40}$ (2013) demonstrated that biofilm formation is dependent on Candida spp. and that, although C. albicans is more prevalent, biofilm production was higher in $C$. glabrata isolates, followed by C. tropicalis, C. albicans and $C$. krusei. These findings reinforce the importance of research such as the current study involving less prevalent species, but with a high potential for virulence. The present research evaluated study evaluated the effect of different solutions against $C$. tropicalis. The authors are unaware of previous studies that performed the same analysis. Limitations of the present study included the lack of evaluation using a mixed biofilm, clinical strains, mature biofilms and a long period of biofilm formation; this would be important for future studies and to facilitate the proximity to the clinical reality. Moreover, the results of this in vitro study are preliminary and important to show the behavior of the 3 Candida species evaluated when exposed to $\mathrm{NaOCl}$, Chloramine $\mathrm{T}$ and $R$. communis disinfectants, but they must be interpreted with caution, since the general health of the host (immunological conditions), local conditions of the oral cavity (quality and quantity of saliva; $\mathrm{pH}$; hygiene), conditions of the dentures and individuals' adherence to the proposed protocols, can influence the extrapolation of the results to clinical reality. 


\section{Conclusions}

$\mathrm{NaOCl} 0.25 \%$ was most effective than the other solutions in reduction of CFU count, cell metabolism, hyphae growth, living cells of all Candida species and biofilm removal. All solutions have not changed the enzymes productions by $C$. albicans and $C$. tropicalis, but $\mathrm{NaOCl}$ caused increased in proteinase production by C. glabrata. CT $0.5 \%$ was effective in decreasing of CFU count of $C$. tropicalis and cell metabolism of C. albicans and C. glabrata. RC $10 \%$ reduced only the CFU count of $C$. glabrata, but decrease the cellular metabolism of C. albicans and C. glabrata.

СТ0.5\% was better than $\mathrm{RC} 10 \%$ in the biofilm removal and decrease of living cells of $C$. albicans and C. tropicalis, whereas RC $10 \%$ was more effective in the biofilm removal of C. glabrata. CT $0.5 \%$ and RC $10 \%$ were similar for the number of $C$. glabrata living cells and hyphal growth of $C$. albicans. In general, the Chloramine $\mathrm{T}$ at $0.5 \%$ achieved better results than Ricinus communis at $10 \%$, favoring the creation of specific products for denture users. Adjustments in the formulations of RC $10 \%$ are necessary.

\section{Acknowledgement}

Prof. Gilberto Chierice (ICQ/Sao Carlos, USP) for providing the $R$. communis solution.

\section{Conflicts of interest}

There are no conflicts of interest.

\section{Authors' contributions}

Badaró, Maurício Malheiros: Data curation (Equal); Formal analysis (Equal); Investigation (Equal); Methodology (Equal); Writing-original draft (Equal); Writing-review \& editing (Equal). Bueno, Frank Lucarini: Data curation (Equal); Investigation (Equal). Araújo, Camila Borba: Data curation (Equal); Investigation (Equal). Makrakis, Lais Ranieri: curation (Equal); Investigation (Equal). Oliveira, Viviane de Cassia: Conceptualization (Equal); Data curation (Equal); Investigation (Equal); Methodology (Equal). Macedo, Ana Paula: Formal analysis (Equal); Software (Equal). Paranhos, Helena de Freitas Oliveira: Conceptualization (Equal); Methodology (Equal); Supervision (Supporting). Silva, Cláudia Lovato: Conceptualization (Equal); Formal analysis (Equal); Funding acquisition (Equal); Methodology (Equal); Project administration (Equal);
Resources (Equal); Software (Equal); Supervision (Equal); Validation (Equal); Visualization (Equal); Writing-original draft (Equal); Writing-review \& editing (Equal).

\section{References}

1- Badaró MM, Bueno FL, Arnez RM, Oliveira VC, Macedo AP, Souza RF, et al. The effects of three disinfection protocols on Candida spp., denture stomatitis, and biofilm: a parallel group randomized controlled trial. J Prosthet Dent. 2020;124(6):690-8. doi: 10.1016/j.prosdent.2019.09.024 2- Coulthwaite L, Verran J. Potential pathogenic aspects of denture plaque. $\mathrm{Br}$ J Biomed Sci. 2007;64(4):180-9. doi: 10.1080/09674845.2007.11732784 3- Miceli MH, Diaz JA, Lee SA. Emerging opportunistic yeast infections. Lancet Infect Dis. 2011;11(2):142-51. doi: 10.1016/S1473-3099(10)70218-8 4- Przybylowska D, Mierzwinska-Nastalska E, Rubinsztajn R, Chazan R, Rolski $D$, Swoboda-Kopec $E$. Influence of denture plaque biofilm on oral mucosal membrane in patients with chronic obstructive pulmonary disease. Adv Exp Med Biol. 2015;839:25-30. doi: 10.1007/5584_2014_42 5- Kołaczkowska A, Kołaczkowski M. Drug resistance mechanisms and their regulation in non-albicans Candida species. J Antimicrob Chemother. 2016;71(6):1438-50. doi: 10.1093/jac/dkv445

6- Luo G, Samaranayake LP. Candida glabrata, an emerging fungal pathogen, exhibits superior relative cell surface hydrophobicity and adhesion to denture acrylic surfaces compared with Candida albicans. APMIS. 2002;110(9):601-10. doi: 10.1034/j.1600-0463.2002.1100902.x 7- Panagoda GJ, Ellepola AN, Samaranayake LP. Adhesion to denture acrylic surfaces and relative cell-surface hydrophobicity of Candida parapsilosis and Candida albicans. APMIS. 1998;106(7):736-42.

8- Muadcheingka T, Tantivitayakul P. Distribution of Candida albicans and non-albicans Candida species in oral candidiasis patients: correlation between cell surface hydrophobicity and biofilm forming activities. Arch Oral Biol. 2015;60(6):894-901. doi: 10.1016/j.archoralbio.2015.03.002 9. Calderone RA, Fonzi WA. Virulence factors of Candida albicans. Trends Microbiol. 2001;9(7):327-35. doi: 10.1016/s0966-842x(01)02094-7

10- Naglik JR, Challacombe SJ, Hube B. Candida albicans secreted aspartyl proteinases in virulence and pathogenesis. Microbiol Mol Biol Rev. 2003;67(3):400-28. doi: 10.1128/mmbr.67.3.400-428.2003

11- Healey KR, Jimenez Ortigosa C, Shor E, Perlin DS. Genetic drivers of multidrug resistance in Candida glabrata. Front Microbiol. 2016;7:1995. doi: 10.3389/fmicb.2016.01995

12- Arruda CN, Salles MM, Badaró MM, Oliveira VC, Macedo AP, Silva-Lovato $\mathrm{CH}$, et al. Effect of sodium hypochlorite and Ricinus communis solutions on control of denture biofilm: a randomized crossover clinical trial. J Prosthet Dent. 2017;117(6):729-34. doi: 10.1016/j.prosdent.2016.08.035 13- Badaró MM, Salles MM, Leite VM, Arruda CN, Oliveira VC, Nascimento $C D$, et al. Clinical trial for evaluation of Ricinus communis and sodium hypochlorite as denture cleanser. J Appl Oral Sci. 2017;25(3):324-34. doi: 10.1590/1678-7757-2016-0222

14- Gama MC, Oliveira DG, Silva PM, Ordinola-Zapata R, Duarte $\mathrm{MH}$, Porto VC. Antifungal activity of $4 \%$ chlorhexidine and $2 \%$ sodium hypochlorite against Candida albicans biofilms. Gen Dent. 2015;63(5):43-7.

15- Pellizzaro D, Polyzois G, Machado AL, Giampaolo ET, Sanitá $P V$, Vergani CE. Effectiveness of mechanical brushing with different denture cleansing agents in reducing in vitro Candida albicans biofilm viability. Braz Dent J 2012;23(5):547-54. doi: 10.1590/s010364402012000500013 
16- Salles MM, Badaró MM, Arruda CN, Leite VM, Silva-Lovato CH, Watanabe $\mathrm{E}$, et al. Antimicrobial activity of complete denture cleanser solutions based on sodium hypochlorite and Ricinus communis - a randomized clinical study. J Appl Oral Sci. 2015;23(6):637-42. doi: 10.1590/1678-775720150204

17- Salles MM, Oliveira VC, Souza RF, Silva CH, Paranhos HF. Antimicrobial action of sodium hypochlorite and castor oil solutions for denture cleaning - in vitro evaluation. Braz Oral Res. 2015;29:1-6. doi: 10.1590/1807-3107BOR-2015.vol29.0104

18- Felton D, Cooper L, Duqum I, Minsley G, Guckes A, Haug S, et al. Evidence-based guidelines for the care and maintenance of complete dentures: a publication of the American College of Prosthodontists. J Am Dent Assoc. 2011;142 Suppl 1:1s-20s. doi: https://doi.org/10.14219/ jada.archive. 2011.0067

19- Badaró MM, Salles MM, Arruda CN, Oliveira VC, Souza RF, Paranhos $\mathrm{HF}$, et al. In vitro analysis of surface roughness of acrylic resin exposed to the combined hygiene method of brushing and immersion in Ricinus communis and sodium hypochlorite. J Prosthodont. 2017;26(6):51621. doi: $10.1111 /$ jopr. 12436

20- Chia Shi Zhe G, Green A, Fong YT, Lee HY, Ho SF. Rare case of type I hypersensitivity reaction to sodium hypochlorite solution in a healthcare setting. BMJ Case Rep. 2016;21:2016:bcr2016217228. doi: 10.1136/bcr-2016-217228

21- Andrade IM, Andrade KM, Pisani MX, Silva-Lovato $\mathrm{CH}$, Souza RF, Paranhos HF. Trial of an experimental castor oil solution for cleaning dentures. Braz Dent J. 2014;25(1):43-7. doi: 10.1590/01036440201302327

22- Leite VM, Pinheiro JB, Pisani MX, Watanabe E, Souza RF, Paranhos $\mathrm{HF}$, et al. In vitro antimicrobial activity of an experimental dentifrice based on Ricinus communis. Braz Dent J. 2014;25(3):191-6. doi: 10.1590/0103-6440201302382

23- Panzeri H, Lara EH, Paranhos HF, Silva-Lovato CH, Souza RF, Souza Gugelmin MC, et al. In vitro and clinical evaluation of specific dentifrices for complete denture hygiene. Gerodontol. 2009;26(1):26-33. doi: 10.1111/j.1741-2358.2008.00235.x

24- Pitten FA, Kramer A. Antimicrobial efficacy of antiseptic mouthrinse solutions. Eur J Clin Pharmacol.1999;55(2):95-100. doi: 10.1007/ s002280050601

25- Verardi G, Cenci MS, Maske TT, Webber B, Santos LR. Antiseptics and microcosm biofilm formation on titanium surfaces. Braz Oral Res. 2016;30. doi: 10.1590/1807-3107BOR-2016.vol30.0030

26- Takano EH, Busso C, Gonçalves EA, Chierice GO, CatanzaroGuimarães SA, Castro-Prado MA. Inibição do desenvolvimento de fungos fitopatogênicos por detergente derivado de óleo da mamona (Ricinus communis) [The castor oil plant detergent (Ricinus communis) inhibits the asexual development of phytopathogenic fungi]. Cienc Rural [online]. 2007;37(5):1235-40. Portuguese. doi: 10.1590/S010384782007000500003

27- Masten S, Haneke KE. Toxicological summary for Chloramine-T [127-65-1] and p - Toluenesulfonamide [70-55-3] [internet]. 2002 [cited 2020 April 29]. Available from: https://ntp.niehs.nih.gov/ntp/ htdocs/chem_background/exsumpdf/chloraminet_508.pdf
28- Panariello BH, Izumida FE, Moffa EB, Pavarina AC, Jorge JH, Giampaolo ET. Effect of mechanical toothbrushing combined with different denture cleansers in reducing the viability of a multispecies biofilm on acrylic resins. Am J Dent. 2016;29(3):154-60.

29- Arnitz R, Nagl M, Gottardi W. Microbicidal activity of monochloramine and chloramine T compared. J Hosp Infect. 2009;73(2):164-70. doi: 10.1016/j.jhin.2009.06.008

30- Silva MM, Vergani CE, Giampaolo ET, Neppelenbroek KH, Spolidorio DM, Machado AL. Effectiveness of microwave irradiation on the disinfection of complete dentures. Int J Prosthodont. 2006;19(3):28893.

31- Paranhos HF, Coimbra FC, Salles MM, Oliveira VC, Macedo AP, Pagnano VD, et al. In vitro evaluation of the effectiveness of alkaline peroxide solutions in reducing the viability of specific biofilms. Am J Dent. 2019;32(4):201-7.

32- Samaranayake YH, Wu PC, Samaranayake LP, So M. Relationship between the cell surface hydrophobicity and adherence of Candida krusei and Candida albicans to epithelial and denture acrylic surfaces. APMIS. 1995;103(10):707-13.

33- D'Eça A Júnior, Silva AF, Rosa FC, Monteiro SG, Figueiredo PM, Monteiro CA. In vitro differential activity of phospholipases and acid proteinases of clinical isolates of Candida. Rev Soc Bras Med Trop. 2011;44(3):334-8. doi: 10.1590/s0037-86822011005000036

34- Marcos-Arias C, Eraso E, Madariaga L, Aguirre JM, Quindós G. Phospholipase and proteinase activities of Candida isolates from denture wearers. Mycoses. 2011;54(4):e10-6. doi: 10.1111/j.14390507.2009.01812.x

35- Gümrü B, Kadir T, Uygun-Can B, Ozbayrak S. Distribution and phospholipase activity of Candida species in different denture stomatitis types. Mycopathologia. 2006;162(6):389-94. doi: 10.1007/s11046006-0074-1

36- Samaranayake LP, Raeside JM, MacFarlane TW. Factors affecting the phospholipase activity of Candida species in vitro. Sabouraudia. $1984 ; 22(3): 201-7$.

37- Jackson S, Coulthwaite L, Loewy Z, Scallan A, Verran J. Biofilm development by blastospores and hyphae of Candida albicans on abraded denture acrylic resin surfaces. J Prosthet Dent. 2014;112(4):988-93. doi: 10.1016/j.prosdent.2014.02.003

38- Staniszewska M, Bondaryk M, Siennicka K, Kurek A, Orłowski J, Schaller $\mathrm{M}$, et al. In vitro study of secreted aspartyl proteinases Sap1 to Sap3 and Sap4 to Sap6 expression in Candida albicans pleomorphic forms. Pol J Microbiol. 2012;61(4):247-56. doi: 10.33073/pjm-2012034

39- Silva PM, Acosta EJ, Pinto LR, Graeff M, Spolidorio DM, Almeida RS, et al. Microscopical analysis of Candida albicans biofilms on heat-polymerised acrylic resin after chlorhexidine gluconate and sodium hypochlorite treatments. Mycoses. 2011;54(6):e712-7. doi: 10.1111/j.1439-0507.2010.02005.x

40- Sánchez-Vargas LO, Estrada-Barraza D, Pozos-Guillen AJ, RivasCaceres R. Biofilm formation by oral clinical isolates of Candida species. Arch Oral Biol. 2013;58(10):1318-26. doi: 10.1016/j. archoralbio.2013.06.006 